\title{
1 Southern Quebec environmental flow assessments: spatial and temporal
}

\section{2 scales sensitivity}

3 Laureline Berthot ${ }^{1}$, André St-Hilaire ${ }^{1}$, Daniel Caissie ${ }^{2}$, Nassir El-Jabi ${ }^{3}$, Judith Kirby ${ }^{4}$ and

4 Sébastien Ouellet-Proulx ${ }^{4}$

$5 \quad{ }^{1}$ Institut National de la Recherche Scientifique, Centre Eau Terre Environnement, Québec, Canada;

$6 \quad{ }^{2}$ University of Moncton, Civil engineering, Moncton, Canada;

$7 \quad{ }^{3}$ Fisheries and Oceans Canada, Freshwater Habitat Science Section, Moncton, New Brunswick, Canada;

$8{ }^{4}$ Ministère de l'Environnement et de la Lutte contre les Changements Climatiques, Direction générale des 9 politiques de l'eau, Québec, Canada

10

${ }^{1}$ Corresponding author at : Centre Eau Terre Environnement, Institut National de la Recherche Scientifique, 490, rue de la Couronne, Québec, G1K 9A9, Canada. E-mail address: laureline.berthot@ete.inrs.ca (L.Berthot). 


\section{Southern Quebec environmental flow assessments: spatial and temporal}

\section{Scales sensitivity}

\section{ABSTRACT}

14 Faced with increasing demands for water withdrawals and a changing climate, the

15 Quebec Department of Environment and Fight Against Climate Change is reviewing its

16 water withdrawal guidelines to protect riverine ecosystems. For Southern Quebec,

17 guidelines currently limit water withdrawals to a maximum of $15 \%$ of the $7 \mathrm{Q} 2$ (mean 7 -

18 day low flow with a return period of two years) during low flow periods. In this context,

19 one of the issues raised is to investigate measures that help to preserve riverine

20 ecosystems during low flow periods by establishing cut-off flow restrictions. This study

21 compared eight low flow metrics to investigate which can be considered useful metrics to

22 assess environmental flow in Southern Quebec rivers. Using 98 hydrometrics stations

23 with a minimum of 20 years of daily flow data from eight hydrological regions, those low

24 flow metrics were compared to three thresholds based on Tennant Method for monthly

25 and annual temporal scales. The relevance of current hydrological regions delineation

26 was investigated by looking at results within these regions, compared to six groups of

27 stations defined using multivariate analyses. This study emphasizes that assessing

28 environmental flows is linked to the hydrological context of the area of interest, the

29 temporal scale of the historical data available, and the catchment size. The results showed

30 that (1) winter low flows were lower than summer low flows; (2) $23 \%$ to $26 \%$ of the

31 values were under the conservative thresholds for all the metrics depending of the time

32 scale; and (3) the 7Q2, 7Q10 (mean 7-day low flow with a return period of ten years),

33 Q95 and Q90 (95th and 90th percentile on the flow duration curve) are the less 
34 conservative for rivers having a low regime flow. To conclude, assessing several regionally adapted environmental flow metrics is recommended rather than systematically using the 7Q2 for Southern Quebec.

37 KEYWORDS: Environmental flows, temporal scale, hydrological regions, riverine ecosystem sustainability, water sharing guidelines.

\section{RÉSUMÉ}

40 Face à la demande croissante de prélèvements d'eau et aux changements climatiques, le ministère de l'Environnement et de la Lutte contre les changements climatiques du

Au Québec méridional, les prélèvements d'eau sont actuellement limités à un maximum de 15\% du 7Q2 (débit minimum d'une moyenne mobile de 7 jours et une période de retour de deux ans) durant les périodes d'étiage. Dans ce contexte, une étude hydrologique a été faite pour déterminer les débits planchers, en dessous desquels il n'est plus permis de prélever d'eau. Dans cette étude, les résultats de huit métriques ont été comparés à trois seuils issus de la méthode de Tennant, pour des temporalités mensuelles et annuelles, afin de pointer celles pouvant être considérées comme des débits environnementaux. Les débits journaliers, ayant au moins 20 ans de données, proviennent de 98 stations situées dans huit régions hydrographiques. La pertinence de celles-ci a été étudiée en considérant les résultats dans ces régions, mais aussi dans six groupes de stations définis à l'aide d'analyses multivariées. Il ressort que la détermination d'un débit environnemental est liée au contexte hydrologique de la zone d'étude, à la temporalité et à la taille du bassin versant. De plus, les résultats ont montré que (1) les débits hivernaux étaient inférieurs aux estivaux ; (2) $23 \%$ à $26 \%$ des métriques calculées étaient 
57 inférieures aux seuils de restriction, selon l'échelle temporelle; et (3) le 7Q2, 7Q10 (débit

58 minimum d'une moyenne mobile de 7 jours et une période de retour de dix ans), Q95 et

$59 \mathrm{Q} 90\left(95^{\mathrm{e}}\right.$ et $90^{\mathrm{e}}$ percentile des débits classés $)$, sont déconseillés pour les rivières ayant de

60 faibles débits. Enfin, il est recommandé de définir plusieurs débits environnementaux, au

61 lieu d'un seul (7Q2), au Québec méridional.

62 MOTS-CLÉS : Débits environnementaux, échelle temporelle, régions hydrologiques,

63 durabilité des écosystèmes riverains, politique de partage de l'eau.

\section{1. Introduction}

65 Environmental flows are defined as "the quantity, timing, and quality of freshwater flows

66

67

68

69

70 and levels necessary to sustain riverine ecosystems which, in turn, support human cultures, economies, sustainable livelihoods, and well-being” (Arthington et al. 2018). Over ten years after the Brisbane Declaration (2007), this definition asserts an economic dimension provided by the environmental flow assessments and an interdependency between human conditions and the riverine ecosystems sustainability. According to Poff et al. (1997), riverine ecosystems have adapted to their natural flow regime and their sustainability comes from the river dynamics defined by water quality, physical habitat, biotic interactions and energy sources. Floods and medium flows maintain the river structure, establish a link with floodplain habitats, ensure sediment sorting and flushing, stimulate upstream migration and spawning, while low flows may prevent invasive species spread, while protecting habitats (다eman and Dunbar 2004). For 17 fish species of interest identified by Belzile et al. (1997), the summer period concerns mainly the feeding phase of the fish life cycle for the growth and survival of the larval and juvenile fish in the Southern Quebec rivers. 
To characterise the hydrological regime of a river, Poff et al. (1997) developed the

natural flow paradigm, which can be viewed as benchmark flow conditions for

conserving the ecological integrity of rivers, using five main flow characteristics:

magnitude, frequency, duration, timing and variability of a flow event. Over twenty years

later, many jurisdictions of Canadian provinces and across the world define

environmental flows using one or two metrics assessed at relatively broad regional scales, in spite of potentially important hydroclimatic variability within these regions

(Linnansaari et al. 2012). However, over two hundred methodologies exist and have been classified in four categories: hydrological, hydraulic rating, habitat simulation and holistic methods (Tharme 2003; Acreman and Dunbar 2004; Arthington 2012). From hydrological to holistic methods, recent work describes environmental flow assessment as a regional to local issue, to be defined with local stakeholders (water managers, scientific experts, public and private users), and requiring sufficient financial support, knowledge and time (Poff et al. 2010; Acreman and Ferguson 2010; $\underline{\text { Pahl-Wostl et al. }}$ $\underline{2013)}$.

In Southern Quebec, the Department of Environment and Fight Against Climate Change (DEFACC) commissioned a hydrological study to test the relevance of using only the 7Q2 flow metric (low flow with a return period of two years and seven-day duration), throughout the province to manage water withdrawals and riverine ecosystems protection during low flow periods. In the 1990s, this flow metric was used to regulate water withdrawal for golf courses and fish farming and a limitation of 70\% of 7Q2 has been proposed to maintain a minimum flow in rivers (Beaudelin and Bérubé 1994). Subsequently, seasonally low flow restrictions to preserve fish habitats of identified eco- 
103 hydrological regions were proposed by Belzile et al. (1997), which are used by the

104 Department of Wildlife, Forests and Parks (MFFP 1999). Today, the 7Q2 flow metric

105 appears three times in guidelines linked to low flow periods:

106

107

(1) To limit the cumulative effect of water withdrawals to $15 \%$ of the $7 \mathrm{Q} 2$ (DEFACC 2015);

(2) As a minimum flow to manage water sharing, hydraulic structure and water quality following a wastewater or a contaminant discharge (DEHAQ 2015);

(3) To minimize the risks associated with its predicted decrease during summer according to the RCP4.5 climate change scenario (GIEC 2014) for the 2050 horizon (DEFACC 2018).

Presently, no study exists to support the use of the 7Q2 as a low flow limit to sustain riverine ecosystems, on the contrary, this flow metric has been observed to result in extremely low flows in small streams in some regions of Atlantic Canada (e.g., $\underline{\text { Caissie et }}$ al. 2007).

Our first objective was to compare the 7Q2 environmental flow metric with other environmental flow methods used in other jurisdictions for different temporal scales (e.g. yearly and monthly). Through the comparisons, potential environmental flow metrics results were classified from the most to the less conservative and permissive one, using $\underline{\text { Tennant (1976) }}$ and Caissie and El-Jabi (1995) thresholds. In addition, the spatial relevance of the selected metrics was investigated. Our second objective was to compare the current hydrological regions with newly defined hydrological regions, using a multivariate analysis. Current hydrologic regions of Southern Quebec (DEHAQ 2020), a 
125 region of about $730000 \mathrm{~km}^{2}$ (DEFACC 2018) with several thousand streams and rivers,

126 were defined using climate and geographical criteria. Finally, a third objective was to

127 investigate the relationship between the more conservative and permissive environmental

128 flows and catchment size.

129

130

131

134

\section{Methodology}

\subsection{Hydrological data}

Historical daily flow data come from 98 hydrometric stations spread in the eight hydrological regions of Southern Quebec: Baie des Chaleurs et Percé, Saint-Laurent sudest, Saint-Laurent sud-ouest, Outaouais et Montréal, Saint-Laurent nord-ouest, Saguenay et lac Saint-Jean, Saint-Laurent nord-est and the Baies de Hannah et de Rupert (DEFACC 2018). Three criteria were used to select the hydrometric stations:

(1) Being located in one of the aforementioned hydrological regions;

(2) Having a natural flow regime (i.e., unimpeded by dams or reservoirs);

(3) Daily discharge time series must be $\geq 20$ years, as required by Caissie et al. (2007).

The selected stations, with record lengths from 20 to 90 years, are located in tributaries of the Saguenay, Outaouais and St. Lawrence Rivers, in the Gaspésie region, on the northeast St-Lawrence coast and in the Baies de Hannah et de Rupert region.

Given that some of the metrics compared in the present study are used in Atlantic Canada, New England (USA) and the United Kingdom, it is important to note that their climates vary according to oceanic and continental influences. Mean annual precipitation 
146

147

148

149

150

151

152

are from 800 to more than $2000 \mathrm{~mm}$, mean annual runoff from 400 to more than 2000

mm and mean annual of maximum flows from around 1600 to $12600 \mathrm{~mm}$ (를 2013).

Ouellet Dallaire et al. (2019) present maps that showed high similarities between the

Southern Quebec area and regions of Atlantic Canada in terms of hydrological, geomorphic and physio-climatic characteristics.

\subsection{Low flow metrics}

The chosen flow metrics were: the mean 7-day low flow with a return period of two and ten years (7Q2 and 7Q10), the $90^{\text {th }}$ and the $95^{\text {th }}$ percentiles on the flow duration curve (Q90 and Q95), derivatives from the median monthly flow (Q50), and derivatives from $70 \%$ of the median monthly flow (70\%Q50). The 7Q10 flow metric was used in the United-States mainly as a minimum flow calculation to maintain water quality (for dilution purpose); however, it has been used in some cases to calculate environmental flows (Linnansaari et al. 2012). The 7Q10 was criticised in the literature because of the low flow values it provided, particularly for rivers with relatively low baseflows (Belzile et al. 1997). The 7Q10 was deemed insufficient for fisheries protection as an environmental flow method by Caissie et al. (2007) and fish habitat protection (Tennant 1976). Nevertheless, the 7Q10 was included in the present study for comparison purposes with other flow metrics. The Q90 flow metric was tested in New Brunswick, as a potential environmental flow method (Caissie and El-Jabi 1995, Caissie et al. 2007) and results showed that it most likely provided insufficient flows for fish and fisheries protection, particularly during low flow periods (similar results to the 7Q10). The Q95 flow metric was developed in the United-Kingdom (Acreman and Ferguson 2010) and the median monthly flow metric (Q50) in New England, U.S. (USFWS 1981). Both of 
169 these flow metrics have been used to calculate environmental flows in these respective

170 regions. The Q50 flow metric for the month of August (AQ50) was also used in New

171 England mainly through regional studies for ungauged river (Linnansaari et al. 2012).

172 Notably, the Q50 for August is also called the Aquatic Base Flow (Linnansaari et al.

173 2012). The AQ50 flow metric will also be calculated in the present study, as well as the

174 median flow for the lowest flow month (i.e., lowest Q50 or LQ50), as the lowest flow

175 month could be different than the month of August. In Caissie et al. (2014), the LQ50

176 was shown to be a relevant environmental flow metric in New Brunswick (generally

177 occurring in August and September). The 70\% of Q50 which is a variant of the Q50

178 method has been used in the province of Prince Edward Island for environmental flow

179 calculations (Caissie et al. 2014). This flow metric was also be calculated in the present

180 study, including the 70\%Q50 for August (70\%AQ50) as well as the 70\%Q50 during the

181 lowest flow month (70\%LQ50). Therefore, the above flow metrics were selected to

182 evaluate potential environmental flow methods in Southern Quebec with a specific

183 attention to the results of the $7 \mathrm{Q} 2$ flow metric.

\subsection{Environmental flows in Southern Quebec}

To evaluate and compare the potential environmental flow metrics, several thresholds

186 were calculated using the mean annual flow (MAF). Tennant (1976) established

187 environmental flow thresholds based on biological and hydrological data from a ten-year

188 study of Montana, Wyoming and Nebraska rivers (U.S.). In addition, 17 years of USGS

189 flow data from stations in 21 other states were also used in their study. Tennant (1976)

190 concluded that, in general, flows lower than the $10 \%$ MAF most likely cannot conserve

191 the riverine ecosystems and suggested a value closer to $30 \%$ MAF to maintain good 
192 habitat conditions. Also, other studies have used environmental flows based on the MAF,

193 while this metric has to be adapted to different climatic regions (Acreman and Dunbar

194 2004). For example, $25 \%$ of the MAF (25\%MAF) was historically used as a target

195 environmental flow in Nova Scotia (Linnansaari et al. 2012) and in New Brunswick

196 (Caissie and El-Jabi 1995) to preserve the ecological integrity of rivers. In the present

197 study, three thresholds (30\%, 25\% and 10\% of MAF) were used as potential benchmarks

198 for comparison. In addition, recommendation of Belzile et al. (1997) related to low flow

199 restrictions to preserve fish habitats in Southern Quebec can be considered for discussion.

200 These are the Aquatic Base Flow (AQ50) during summer periods, to maintain rearing and

201 feeding habitat of all species and the eel migration in localised areas, the $25 \% \mathrm{MAF}$

202 during winter periods for the protection of incubating eggs, and the $50 \%$ of the MAF in

203 the Montérégie and the Outaouais regions, respectively along the St. Lawrence River on

204 the south coast and along the Outaouais River (Belzile et al. 1997). To compare low flow

205 metrics, this study focuses on winter (January to March) and summer (July to September)

206 low flow periods.

\subsection{Frequency analysis, statistical non-parametric tests and multivariate analysis}

208 The 7Q2 and 7Q10 flow metrics are calculated using low flow frequency analysis. This is

209 a predictive statistical method to calculate the probability of reaching or exceeding a flow

210 value for a specific river (Meylan et al. 2008) as shown in the Equation (1) for low flows:

$$
t(x)=\frac{1}{1-p}
$$

$212 t(\mathrm{x})$ : return period of a flow related to a given event $x$ (years); 
$213 p$ : probability of exceedance, such as $\mathrm{p}=1-\mathrm{F}(\mathrm{x}, \Theta)$, where $\mathrm{F}$ is the cumulative probability

214 distribution and where $\mathrm{x}$ and $\Theta$ are the probability distribution parameters.

215 In this study, several probabilistic distributions for low flow frequencies (WMO 2008,

216 Smakhtin 2001) were tested, including Generalized Extreme Value (GEV), Weibull and

217 Gumbel. A statistical distribution was fitted to annual and monthly minimum of the

218 seven-day moving averages using the maximum likelihood method. Independence

219 (Wilcoxon-Mann-Whitney test), stationarity (Mann-Kendall test) and homogeneity

220 (Breusch-Pagan test) conditions were tested. The Kolmogorov-Smirnov and Chi-square

221 tests were applied to confirm the hypothesis that the selected statistical distributions were

222 adequate, given the fitted samples. Finally, Akaike and Bayesian information criteria

223 were used to select the distribution that best fitted the empirical quantile values or

224 observed flood values. As for New Brunswick environmental flows characterization (El-

225 Jabi and Caissie 2018), the GEV distribution presented best fit while the overall second

226 best fit was with the Weibull distribution. Therefore, following Kite (1978) advocating

227 the type III extreme-value distribution function to assess low flows, GEV was thus

228 selected, with cumulative probability density function defined in Equation (2):

$$
F(x ; \mu, \sigma, \varepsilon)=\exp \left\{-\left[1+\varepsilon\left(\frac{x-\mu}{\sigma}\right)\right]^{-1 / \varepsilon}\right\}
$$

230 With $\varepsilon, \mu$ and $\sigma$, which are respectively the shape, location and scale parameters of the

231 distribution, $\sigma$ and $1+\varepsilon\left(\frac{x-\mu}{\sigma}\right)>0$. When independency, stationary and/or homogeneity

232 conditions were not accepted, standardized residuals, high-leverage points and normal Q-

233 Q plots were made to identify outliers data and remove them. 
Hydrometric stations were sorted by their low flow characteristics using a

235 Principal Component Analysis (PCA), based on a methodology used by Daigle et al.

236 (2011). PCA is a multivariate statistical approach computing linear combinations

237 (principal components, or PC) of original variables to maximize the explained variance

238 while maintaining orthogonality between PCs. As in Daigle et al. (2011), PCA was used

239 to reduce 71 hydrological flow indices, drawn mainly from Hersh and Maidment (2006)

240 and Olden and Poff (2003) studies, calculated and standardized for each station, while

241 retaining at least one low flow indices per characteristic (amplitude, duration, frequency,

242 timing, variability). Then, the selected hydrological indices were used in an

243 agglomerative (ascendant) hierarchical clustering, often used for regional analyses (Poff

244 and Ward 1989), to statistically group the hydrometric stations by similarities in several

245 clusters, called PC-HC. A hierarchical clustering calculates a Euclidean distance as a

246 measure of similarity between stations using the selected indices, and groups them

247 using average-linkage (comparison of group average distances). After grouping station in

248 PC-HC regions, two non-parametric ANOVA tests were used to compare groups. This

249 analysis allowed to confirm that each PC-HC group was significantly different from the

250 others. The Kruskal-Wallis test permits a grouping of populations with equal medians $\left(\mathrm{H}_{0}\right.$

251 not rejected for $\mathrm{p}$-value > 0.05). Then, the Wilcoxon-Mann-Whitney test was used as a

252 post-hoc test to confirm or infirm that group pairs were from the same population $\left(\mathrm{H}_{0}\right.$

253 accepted for $\mathrm{p}$-value $>0.05)$.

\section{3. Results}

2553.1 Overview of low flow results

256 Figure 1 represents the number of hydrometric stations (of the 98 pre-selected) having 
257 their eight associated flow metrics value below the two hypothetic conservative

258 (30\%MAF, 25\% MAF) and non-conservative (10\%MAF) thresholds. Results are

259 presented for inter-annual and monthly temporal scales. March and August were selected

260 as they typically represent the lowest flow month of the winter and summer periods.

261 When compared to the 10\%MAF threshold, the 7Q10, Q95 and 7Q2 flow metrics present

262 the lowest flow values with respectively 43, 24 and 29 stations under this limit for inter-

263 annual data (igure 1a). When comparing flow metrics to the same threshold seasonally,

264 August (igure 1b) and March (igire 1c) values of the 7Q10, Q95 and Q90 indicate that

26520 to 27 stations are below. The AQ50 flow metric have the highest values for all the

266 periods. Moreover, the differences of the number of stations show that the summer values

267 are the highest, then the winter values and finally the inter-annual values. Results of the

268 7Q2 flow metric for August are close to the 70\%AQ50, whereas higher than the

$26970 \% \mathrm{AQ} 50$ for March and the inter-annual period. Considering the results for the 98

270 stations, it appears that (1) winter low flow metrics are lower than summer low flow

271 metrics; (2) the AQ50 presents the highest values for the three temporal scales, and is

272 considered as the most conservative metric, and (3) $23 \%$ (26\%) of the AQ50 values

273 results, are $\leq 25 \% \mathrm{MAF}$ (and 30\%MAF) conservation threshold.

\section{$274 \quad 3.2$ New hydrological regions}

275 PCA was used to select explanatory hydrological indices (HI) used to generate new

276 regions among 71 listed by Daigle et al. (2011) to explain low flow characteristics of the

277 hydrometric stations as defined by Poff et al. 1997: amplitude (A), duration (D),

278 frequency (F), timing (T), variability (V). Factorial loadings allowed the removal of

279 redundant (i.e. highly correlated) variables and to select six HI that explained $79 \%$ of the 
variance. Table 1 lists the $\mathrm{HI}$ retained to make the ascendant hierarchical clustering. The original abbreviation of the $\mathrm{HI}$ are also provided for cross-reference with Daigle et al.

282 (2011). Figure 2 presents the hydrometric stations grouped by PC-HC and the eight

283 hydrological regions limits. PCA and the hierarchical clustering permitted a grouping of

284 the Saguenay and Gaspésie stations (PC-HC1; areas south and north shores of St-

285 Lawrence River). PC-HC2 stations are located along the St-Lawrence River whereas the 286 PC-HC3 and PC-HC5 stations are in the southwestern area. The PC-HC6 stations are in 287 the north-western area with four stations located on the Quebec north shore. The PC288 HC4 stations are mainly in the western part of the province (both southern and northern 289 part of the province). Figure 3 shows new PC-HC groups of stations resulting from 290 hierarchical clustering. The groups PC-HC1, PC-HC2 and PC-HC5 have a mean 291 catchment size of approximately $1600 \mathrm{~km}^{2}$ but different number of stations $(30 ; 15 ; 7)$ and 292 mean of MAF $\left(25.7 ; 21.2 ; 17.2 \mathrm{~L} . \mathrm{s}^{-1} \cdot \mathrm{km}^{-2}\right)$. The groups PC-HC4 and PC-HC6 have 293 different mean catchment size (18 087; $\left.8509 \mathrm{~km}^{2}\right)$, number of stations $(19 ; 16)$ and 294 similar mean of MAF $\left(19.1 ; 19.3 \mathrm{~L}^{-1}{ }^{-1} \cdot \mathrm{km}^{-2}\right)$. The PC-HC3, a region of eleven stations, 295 has the smallest mean catchment size $\left(628 \mathrm{~km}^{2}\right)$ and the lowest mean of MAF (16.6 L.s

$296{ }^{1} \cdot \mathrm{km}^{-2}$ ). Non-parametric ANOVA tests were used to investigate inter-region differences 297 in environmental flow metrics for the original regions (R0s) as well as for the PC-HC 298 groups. Hydrological regions and PC-HC groups were significantly different, as were 299 metric results.

\subsection{Comparison of low flow metrics within historical and new hydrological regions}

301 In Figures 4 and 5, the box plots present the range of mean values of the inter-annual

302 flow metrics divided by the MAF for hydrological regions and PC-HC groups. Each time, 
the flow metrics were ordered from the less to the more conservative, with the latter implying the lower risk of impacts on the ecosystem. Results were compared to the three \% MAF thresholds (dotted lines). The classification of flow metrics is the same for R01 and PC-HC, R02 and PC-HC2, and R04 and PC-HC5, taken in pairs, and for R05, R06, PC-HC4 and PC-HC6. The R03, R07, R08 and PC-HC3 regions have metric orders that 308 are different than all other regions. Using Tennant's (1976) threshold ( $\geq 30 \% \mathrm{MAF})$, in 309 ascending order, the 70\%AQ50, LQ50 and AQ50 flow metrics can be considered as 310 adequate within hydrological regions (Figure 4), and the 70\%AQ50 and Q90 flow

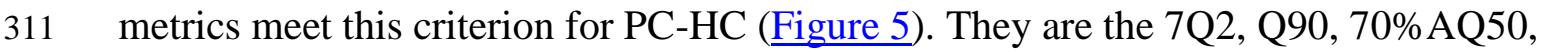
312 AQ50 and LQ50 flow metrics for hydrological regions and the 7Q2, LQ50, 70\%AQ50 313 and 70\%LQ50 flow metrics for PC-HC, according to Caissie and El-Jabi (1995)

314 threshold ( $\geq 25 \% \mathrm{MAF}$ ). Metric orders seem to be independent from the mean catchment 315 sizes and the number of hydrometric stations. More precisely, the AQ50 flow metric is 316 the most conservative environmental flow approach with $80 \%$ to $100 \%$ of flows higher 317 than the 30\%MAF threshold for six R0s and four PC-HC. The 7Q10 flow metric is the 318 less conservative approach with $50 \%$ to $100 \%$ of values above $10 \%$ MAF for three R0s 319 and three PC-HC. Considering the 7Q2 flow metric, more than half of the results were 320 between $10 \%$ MAF and 25\%MAF thresholds for six R0s and four PC-HC. In the PC-HC2 321 and $\mathrm{PC}-\mathrm{HC} 3$ groups, none of the metrics can be considered as protective as the 322 environmental flow guidelines suggested by $\underline{\text { Tennant (1976) }}$ and Caissie and El-Jabi 323 (1995).

324 The inter-quartile range (IQR differences between $75^{\text {th }}$ and $25^{\text {th }}$ percentiles) of the 325 boxes in Figures 4 and 5 portrays the variability as a percentage of MAF of each flow 
metrics by regions of PC-HC groups. By R0 and by flow metric, the minimum of the differences varied from 1.8\% (R06; 7Q2) to 6.8\% (R05; 7Q10) and the maximum from 4.2\% (R01; AQ50) to 28.7\% (R08; AQ50). For PC-HC groups, IQR represented a minimum of $0.6 \%(\mathrm{PC}-\mathrm{HC} 2 ; 7 \mathrm{Q} 2)$ to $5.2 \%(\mathrm{PC}-\mathrm{HC} 4 ; 70 \% \mathrm{LQ} 50)$ and a maximum from 7.5\% (PC-HC2; LQ50) to 35.1\% (PC-HC6; AQ50). Looking at the mean of those percentages by flow metrics through $\mathrm{R} 0$ and $\mathrm{PC}-\mathrm{HC}$ groups, the mean differences is lower for the 7Q10, 7Q2, 70\%LQ50, Q95, Q90 and LQ50 flow metrics of the PC-HC comparing to the R0, whereas for the 70\%AQ50 and the AQ50 flow metrics, IQR are smaller in $\mathrm{R} 0$ compared to $\mathrm{PC}-\mathrm{HC}$. This indicates that PC-HC groups are generally more homogeneous than the historic hydrological regions in the context of environmental flow metrics selection.

\subsection{Monthly low flow metrics within PC-HC}

Figure 6 presents radial plots of the eight metrics applied to monthly flows, standardized by dividing their value by the MAF, for each PC-HC group. The y-axis has been limited to $100 \%$ of the MAF and presented on a logarithmic scale thus truncating higher monthly results. The plots show the four periods for each PC-HC, which are from the higher to the lower flow values, from March to July, September to January, July to September and from January to March. The lowest monthly flow values have been found for August and September during summer, for all PC-HC. During winter, the lowest flow month for PCHC1, PC-HC4 and PC-HC6 is March, and February for the rest of the PC-HC.

For August and September, the classification of the flow metrics, in ascending order from the less to the more conservative, is: 7Q10, Q95, Q90, 7Q2, 70\%LQ50 / 70\%AQ50 and the LQ50 / AQ50 for all PC-HC except the PC-HC4 having the 7Q2 flow 
metric on the second to last. The metrics order for the summer is quite similar to the inter-annual PC-HC2 and PC-HC3 metric orders (Figure 5), excepting that the 7Q2 is more conservative than the Q95 and Q90 flow metrics for summer results. For monthly results, it appeared that the 7Q10 and Q95, the 70\%LQ50 and 70\%AQ50 and the LQ50 and AQ50 values were pairs of very similar values for all PC-HC, as for the 7Q2 and 70\%LQ50 values for PC-HC5 and PC-HC6. Differences were found when comparing monthly metrics to the 10\%MAF, 25\% MAF and 30\%MAF thresholds. PC-HC2 and PCHC3 summer results were similar to inter-annual results (Figure 5). All the flow metrics are under the 25\% MAF limit, with the 7Q10, Q95, Q90 under the 10\%MAF, with the addition of the 7Q2 for PC-HC3. For PC-HC1 and PC-HC5, the 7Q2, 70\%LQ50 / 70\%AQ50 and LQ50 / AQ50 flow metrics are above the 30\%MAF threshold. At last, PC-HC4 and PC-HC6 presented all flow metrics above the 30\% MAF.

In February and March, the classification of the flow metrics is different for each group. However, the winter metric orders of PC-HC1, PC-HC4, PC-HC5 and PC-HC6 are quite similar to their inter-annual classifications respectively (Figure 5), with, as for summer results, the 7Q2 that is more conservative than the Q95 and Q90. The 7Q10, Q95 and Q90 are the less conservative, with the 7Q10 and the Q95 having similar values for all PC-HC. As for summer values, the winter Q90 and 70\%LQ50 are substantially similar for PC-HC1, PC-HC4, PC-HC5 and PC-HC6, as the 7Q2, 70\%LQ50 and 70\%AQ50 for PC-HC2, and the 7Q2, 70\%LQ50 and AQ50 for PC-HC3. The AQ50 is the more conservative flow metric except for PC-HC2 and PC-HC5 where LQ50 is similar and for PC-HC3 where LQ50 is more conservative. When compared to the 30\%MAF threshold, the 70\%AQ50 and AQ50 flow metrics are above it for PC-HC1 and PC-HC6, as the 7Q2, 
LQ50, 70\%AQ50 and AQ50 for PC-HC4 and PC-HC5, with the 70\%LQ50 in addition to the latter.

For monthly results, it appears that:

(1) Winter low flow values are lower than summer flows;

(2) Summer values influenced inter-annual values for the PC-HC2 and PC-HC3 and winter values influenced inter-annual values for the rest of PC-HC;

(3) None of the flow metric methods are conservative enough to protect the aquatic ecosystems, in PC-HC2 and PC-HC3, when using Tennant (1976) and Caissie and El-Jabi (1995) recommendations during both of low flow periods. These two groups represent $25 \%$ of the hydrometric stations considered in this study, generally located along the St-Lawrence River on the south shore.

\subsection{Environmental flow values and catchment size}

Figure 7 presents the more conservative and restrictive inter-annual flow metrics (in $\mathrm{m}^{3} / \mathrm{s}$ ) above the 30\%MAF threshold, as a function of catchment sizes for each PC-HC and for all Southern Quebec (Inter-annual, August and March data as in Figure 1). As expected, Figure 7 shows that low flow metrics of rivers and catchment size are correlated (Daigle et al. 2011). The equation and the $\mathrm{R}^{2}$ values of the power functions of each environmental flow plotted were shown. The $\mathrm{R}^{2}$ value is 0.89 for Southern Quebec results, and from 0.92 to 0.99 for the PC-HC, with the coefficients of the power functions close to 1 . In

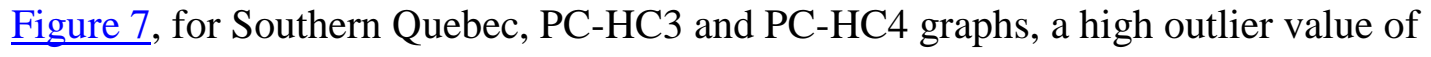
catchment size is presented albeit excluded from the model. The largest drainage area $\left(146000 \mathrm{~km}^{2}\right)$, is that of the Mille-Iles River. Also, when none of the calculated flow 
metric was conservative enough, the $30 \% \mathrm{MAF}$ was proposed as an environmental flow.

395 Compared to the $30 \% \mathrm{MAF}$ threshold, the $70 \%$ AQ50 flow metric was the more conservative and restrictive for the Southern Quebec inter-annual values. The AQ50 is

397 the most conservative flow metric for the Southern Quebec, August and March monthly 398 results. For PC-HC, the results are the same as in Figure 5, regarding the selection of the 399 more conservative and restrictive flow metric, using the power functions. Thus, using 400 PC-HC groups lead to the selection of different sufficiently conservative flow metrics for 401 these hydrological regions, but the correlation with catchment size remains strong $\left(\mathrm{R}^{2}>\right.$ $4020.9)$ in each case.

$\underline{\text { Table } 2}$ is a review of the results for 21 different contexts: for inter-annual,

404 summer and winter periods, by PC-HC and for the whole of Southern Quebec. Table 2

405 gives also the number of hydrometric stations and their location, the mean catchment 406 size, the summer and winter low flow months, and characteristics of rivers for each PC407 HC. The 10\%MAF, 30\%MAF ( $\underline{\text { Tennant 1976) }}$ and the 25\%MAF (Caissie and El-Jabi $408 \quad 1995)$ are used as potential thresholds to discuss the risk of using some flow metrics for 409 riverine ecosystems in contrast with human's benefits. For the whole Southern Quebec, 410 the LQ50 (> 25\%MAF) and the 70\%AQ50 (> 30\%MAF) flows metrics are the less risky 411 and pose greater restrictions on water withdrawal. It is respectively the same for PC-HC5 412 and PC-HC6 groups with the 70\%LQ50 and the LQ50 flow metrics and the Q90 and the $41370 \% \mathrm{AQ} 50$ flow metrics. Because all of their values were superior to the $30 \% \mathrm{MAF}$, the $41470 \% \mathrm{AQ} 50$ and the Q90 flow metrics are the less risky and more restrictive metrics for 415 PC-HC1 and PC-HC4 respectively. In groups PC-HC2 and PC-HC3, flow metrics 416 considered were $\leq 25 \% \mathrm{MAF}$, hence the latter (or $30 \% \mathrm{MAF}$ ) was proposed as possible 
417 environmental flow metrics. These two groups include approximately $25 \%$ of the

418 hydrometric stations.

419 Obviously, the selected, less risky flow metric to protect the aquatic ecosystems of the 420 rivers changes depending of the hydrological context, for the whole of Southern Quebec 421 or for each PC-HC groups. The selected metric changes also depending on the temporal 422 scale (annual or monthly). Chosen flow metrics for inter-annual results are mainly based 423 on descriptive statistics (70\%AQ50, LQ50, 70\%LQ50, 30\%MAF, 25\%MAF, Q90). For 424 the summer periods, presenting the highest flow values, and for winter periods, frequency 425 analyses flow metrics (7Q10, 7Q2) can be chosen for PC-HC1, PC-HC4, PC-HC5 and 426 PC-HC6 and for PC-HC4 and PC-HC5 groups. Frequency analyses flow metrics are 427 interested to consider extreme flow events related to the climate change.

\section{Discussion and conclusion}

434 2010). 2010).

A total of 98 natural flow regime gauged rivers with discharge time series $\geq 20$ years were pre-selected for this study. Indeed, gauged rivers with shorter time series and ungauged rivers for which regional statistical analyses would be required were not taken into account. Those limits are discussed in Caissie and El-Jabi (1995), Richter (2010), as well as their adaptation to altered flow regimes ( $\underline{\text { Richter et al. 1996; }} \underline{\text { Poff and Zimmerman }}$

The main questions that triggered this hydrological study were: should environmental flow guidelines vary temporally and spatially to improve the management of water withdrawals in Southern Quebec rivers? More precisely: are the historical hydrological regions adequately defined for the low flow characteristics of Southern Quebec rivers? Which thresholds can be fixed to protect fish habitat and preserve the 
440 river`s ecological integrity during low flow periods? Is the single use of the 7Q2 flow

441 metric relevant across all Southern Quebec rivers? Finally, is there a link between

442 environmental flow and catchment size?

$443 \quad$ First, a principal component analysis and an ascendant hierarchical clustering 444 were used to group hydrometric stations in six PC-HC clusters. Using this method, rivers 445 in the same group need not to be geographically close (e.g. PC-HC1), but can be (i.e. 446 along the St-Lawrence River in PC-HC2). The new PC-HC groups show less inter-station 447 variance for the lowest flow metrics (7Q10, 7Q2, Q95, Q90), when compared to inter448 station variance in historical hydrological regions. Hence, the PC-HC groups can be a 449 useful alternative to define environmental flow guidelines by regions that have more 450 similar low flow metrics than the historical regions. scales (monthly and annually).. In summary:

- PC-HC grouped hydrometric stations according to homogenous low flow values, of the 7Q10, Q90, Q95, 70\%LQ50, LQ50, 70\%LQ50 and AQ50 at different temporal in contrast with contiguous geographical regions. In addition, the relationship between key low flow metric and catchment size is often slightly to significantly better in PC-HC regions than for the whole of Southern Quebec;

- The 7Q10, Q95, Q90 and 7Q2 flow metrics are potentially more risky for the riverine ecosystems compared to the 70\%LQ50, LQ50, 70\%AQ50, AQ50, 70\%Q50 flow metrics, depending of the time scale;

- 7Q10 and Q90 flow metrics could be proposed as environmental flow metrics for rivers having the highest flow regime; 
- Accounting for different temporal scale is essential to assess environmental flows for specific study areas and seasonal metrics may be more adequate than those based on inter-annual means;

- Around $25 \%$ of the hydrometric stations located along the south shore of the St Lawrence River have very low winter and summer flows with all of the metrics resulted in flows lower than 25\%MAF and 30\%MAF. Those rivers are near to the Montérégie region, where Belzile et al. (1997) proposed the use of 50\% of the MAF;

- The percentage of the mean annual flow, as 30\%MAF (Tennant 1976) or the 25MAF (Caissie and El-Jabi 1995), can be a relevant flow metrics;

- Inter-annual flow metrics can be greatly influenced by summer (PC-HC2 and PCHC3) and winter low flow variability (PC-HC1, PC-HC4, PC-HC5 and PC-HC6);

The AQ50 flow metric is potentially the less risky as an environmental flow during summer, as stated by Belzile et al.(1997), to protect fish habitats. The main recommendation is the need of using several adapted flow metrics to assess environmental flows and protect riverine ecosystems in opposition of using only one flow metric such as the $7 \mathrm{Q} 2$ to manage water withdrawals for the entire region. 
Table 1. Hydrological indices retained to be used in the ascendant hierarchical clustering

\section{HI Definition}

A7 Mean of the minimums of all May flow values over the entire record $\left(\mathrm{L} . \mathrm{s}^{-1} \cdot \mathrm{km}^{-2}\right)$

A27 5-year annual minimum daily discharge $\left(\mathrm{L.S}^{-1} \cdot \mathrm{km}^{-2}\right)$

D16 3-day minimum divided by the median of the entire record (unitless)

F2 Average number of flow events with flows below a threshold equal to $5 \%$ of the mean flow value for the entire flow record (unitless)

T3 Average Julian date of the seven annual 1-day minimum discharges (Julian date)

V8 Coefficient of variation of annual 7-day minimum flow (unitless) 
Table 2. Review of the results and the more conservative and restrictive flow metrics. For inter-annual, summer and winter periods, by PC-HC, for 25\% MAF and 35\% MAF thresholds, and depending of the MAF or catchment size.*Quoting hydrological sub-classification from Ouellet Dallaire, Lehner and Creed (2019)

\begin{tabular}{|c|c|c|c|c|c|c|c|c|}
\hline & & $\begin{array}{c}\text { Southern } \\
\text { Quebec }\end{array}$ & PC-HC1 & PC-HC2 & PC-HC3 & PC-HC4 & PC-HC5 & PC-HC6 \\
\hline \multicolumn{2}{|c|}{ Hydrometric stations } & 98 & 30 & 15 & 11 & 19 & 7 & 16 \\
\hline \multicolumn{2}{|c|}{$\begin{array}{l}\text { Location of stations in the } \\
\text { southern Quebec }\end{array}$} & - & $\begin{array}{l}\text { Along the } \\
\text { Saguenay } \\
\text { river, } \\
\text { Gaspésie } \\
\text { area }\end{array}$ & $\begin{array}{c}\text { Along the St- } \\
\text { Lawrence } \\
\text { river }\end{array}$ & $\begin{array}{l}\text { Along the St- } \\
\text { Lawrence river } \\
\text { and in the } \\
\text { south-western }\end{array}$ & Western & $\begin{array}{l}\text { South- } \\
\text { western }\end{array}$ & $\begin{array}{c}\text { North-western } \\
\text { and Quebec } \\
\text { north shore }\end{array}$ \\
\hline \multicolumn{2}{|c|}{ Mean of catchment size } & - & $1687 \mathrm{~km}^{2}$ & $1545 \mathrm{~km}^{2}$ & $628 \mathrm{~km}^{2}$ & 18087 km² & $1602 \mathrm{~km}^{2}$ & $8509 \mathrm{~km}^{2}$ \\
\hline \multicolumn{2}{|c|}{$\begin{array}{l}\text { Lower summer monthly } \\
\text { flow }\end{array}$} & August & September & August & August & September & September & September \\
\hline \multicolumn{2}{|c|}{ Lower winter monthly flow } & March & March & February & February & March & March & March \\
\hline \multicolumn{2}{|c|}{$\begin{array}{l}\text { Rivers sizes, regime flow, } \\
\text { variability between } \\
\text { summer and winter } \\
\text { periods, spring melt* }\end{array}$} & - & $\begin{array}{c}\text { Medium rivers } \\
\text { and regime } \\
\text { flows, high } \\
\text { variability, late } \\
\text { melt }\end{array}$ & $\begin{array}{c}\text { Medium } \\
\text { rivers and } \\
\text { regime flows, } \\
\text { low } \\
\text { variability, } \\
\text { early melt }\end{array}$ & $\begin{array}{l}\text { Small rivers, } \\
\text { low regime } \\
\text { flows and } \\
\text { variability, } \\
\text { early melt }\end{array}$ & $\begin{array}{l}\text { Large rivers, } \\
\text { high regime } \\
\text { flows and } \\
\text { variability, } \\
\text { late melt }\end{array}$ & $\begin{array}{c}\text { Medium } \\
\text { rivers and } \\
\text { regime flows, } \\
\text { low } \\
\text { variability, } \\
\text { early to late } \\
\text { melt }\end{array}$ & $\begin{array}{l}\text { Large rivers, } \\
\text { low to high } \\
\text { regime flows, } \\
\text { high } \\
\text { variability, } \\
\text { late melt }\end{array}$ \\
\hline \multirow[b]{3}{*}{$\begin{array}{l}\text { Inter- } \\
\text { annual }\end{array}$} & $>30 \%$ MAF & AQ50 & $70 \% A Q 50$ & $30 \%$ MAF & $30 \% \mathrm{MAF}$ & Q90 & LQ50 & $70 \% A Q 50$ \\
\hline & $>25 \%$ MAF & $70 \% A Q 50$ & $70 \% A Q 50$ & $25 \%$ MAF & $25 \%$ MAF & Q90 & $70 \%$ LQ50 & Q90 \\
\hline & $\leq 10 \% \mathrm{MAF}$ & (1) & No & $\begin{array}{l}\text { 7Q10, 7Q2 } \\
\text { Q95 }\end{array}$ & $\begin{array}{l}\text { 7Q10, 7Q2, } \\
\text { Q95, Q90, } \\
\text { 70\%AQ50, } \\
\text { 70\%LQ50 }\end{array}$ & - & 1 & - \\
\hline
\end{tabular}




\begin{tabular}{|c|c|c|c|c|c|c|c|c|}
\hline \multirow{3}{*}{$\begin{array}{l}\text { Summer } \\
\text { period }\end{array}$} & $>30 \% \mathrm{MAF}$ & AQ50 & $\begin{array}{c}\text { 70\%AQ50 / } \\
\text { 7Q2 / } \\
\text { 70\%LQ50 }\end{array}$ & $30 \% \mathrm{MAF}$ & $30 \% \mathrm{MAF}$ & 7Q10 / Q95 & $\begin{array}{c}\text { 70\%AQ50 / } \\
\text { 7Q2 / } \\
\text { 70\%LQ50 }\end{array}$ & Q95 / 7Q10 \\
\hline & $>25 \% \mathrm{MAF}$ & $\begin{array}{c}\text { LQ50 / } \\
\text { AQ50 }\end{array}$ & Q95 & $25 \% \mathrm{MAF}$ & $25 \% \mathrm{MAF}$ & 7Q10 / Q95 & $25 \% \mathrm{MAF}$ & Q95 / 7Q10 \\
\hline & $\leq 10 \% \mathrm{MAF}$ & - & - & $\begin{array}{c}\text { 7Q10, Q95, } \\
\text { Q90 }\end{array}$ & $\begin{array}{c}\text { 7Q10, Q95, } \\
\text { Q90, 7Q2 }\end{array}$ & - & - & - \\
\hline \multirow{3}{*}{$\begin{array}{l}\text { Winter } \\
\text { period }\end{array}$} & $>30 \% \mathrm{MAF}$ & AQ50 & $70 \% A Q 50$ & $30 \% \mathrm{MAF}$ & $30 \% \mathrm{MAF}$ & 7Q2 & $\begin{array}{c}70 \% \text { LQ50 / } \\
70 \% A Q 50\end{array}$ & $70 \% A Q 50$ \\
\hline & $>25 \% \mathrm{MAF}$ & $\begin{array}{l}\text { LQ50 / } \\
\text { AQ50 }\end{array}$ & 70\%AQ50 & $25 \% \mathrm{MAF}$ & $25 \% \mathrm{MAF}$ & 7Q10 & Q95 / 7Q10 & $25 \% \mathrm{MAF}$ \\
\hline & $\leq 10 \% \mathrm{MAF}$ & - & - & - & $\begin{array}{c}\text { 7Q10, Q95, } \\
\text { Q90 }\end{array}$ & - & - & - \\
\hline
\end{tabular}


Figure 1. Number of stations with metrics under the 30\%MAF, 20\% MAF and 10\% MAF thresholds for inter-annual (a), March (b) and August (c) flow metrics

Figure 2. Hydrometric stations by PC-HC groups compared to original hydrological regions showed by numbers (Quebec map from DEHAQ 2020)

Figure 3. Ascendant hierarchical clustering of hydrometric stations by PC-HC groups: Number of hydrometric stations; Mean catchment sizes; Mean of the MAF in specific flows.

Figure 4. Inter-annual metrics results divided by MAF for hydrological regions, (\#: number of stations, MCS: Mean Catchment Size, horizontal lines: 10\%MAF, 25\%MAF and $30 \% \mathrm{MAF})$

Figure 5. Inter-annual metrics results divided by MAF for PC-HC groups, (\#: number of stations, MCS: Mean Catchment Size, horizontal lines: 10\%MAF, 25\%MAF and $30 \% \mathrm{MAF})$

Figure 6. Mean of monthly metric results divided by MAF for PC-HC groups. Solid black lines and dotted grey lines with round markers, from inside to outside, are respectively the 10\%MAF, 25\%MAF, 30\%MAF, 70\%AQ50 and the AQ50 flow metrics.

Figure 7. Most conservative and restrictive inter-annual flow metrics above the $30 \% \mathrm{MAF}$ threshold, depending on catchment sizes for each PC-HC and Southern Quebec (SQ) 


\section{Acknowledgments}

The authors wish to acknowledge the financial contribution of the Quebec Department of

Environment and Fight Against Climate Change. The contribution of the Quebec Water Expertise

Direction in terms of expertise and data sharing is also acknowledged.

\section{References}

Acreman, M. C., and M. J. Dunbar. 2004. "Defining environmental river flow requirements: A review." Hydrology and Earth System Sciences 8 (5): 861-876. doi: 10.5194/hess-8-861-2004.

Acreman, M. C., and A. J. D. Ferguson. 2010. "EFs and the European Water Framework Directive." Freshwater Biology 55 (1): 32-48. doi: 10.1111/j.1365-2427.2009.02181.x.

Arthington, A. H. 2012. Environmental flows: saving rivers in the third millennium. Berkley: Freshwater ecology series - University of California. doi: 10.1525/california/9780520273696.001.0001.

Arthington, A. H., J. G. Kenne, E. D. Stein, and J. A. Webb. 2018. "Recent advances in environmental flows science and water management: Innovation in the Anthropocene." Freshwater Biology 63 (8): 1022-1034. doi: 10.1111/fwb.13108.

Beaudelin, P., et P. Bérubé. 1994. "Cadre d'analyse des projets de petites centrales hydroélectriques." Document de régie interne, Ministère de l'Environnement et de la Faune, Québec.

Belzile, L., P. Bérubé, V. D. Hoang et M. Leclerc. 1997. "Méthode écohydrologique de détermination des débits réservés pour la protection des habitats du poisson dans les rivières du Québec." Rapport scientifique, Ministère de l'Environnement et de la Faune et Pêches et Océans Canada.

Brisbane Declaration. 2007. "Environmental flows are essential for freshwater ecosystem health and human well-being". Paper presented at the $10^{\text {th }}$ International River Symposium and International Environmental Flows Conference, Brisbane, September 3-6.

Caissie, D., N. El-Jabi. 1995. "Comparison and regionalization of hydrologically based instream flow techniques in Atlantic Canada." Canadian Journal of Civil Engineering 22(2): 235-246. doi: 10.1139/195-033.

Caissie, D, N. El-Jabi, and C. Hébert. 2007. "Comparison of hydrologically based instream flow methods using a resampling technique." Canadian Journal of Civil Engineering 34(1): 66-74. doi: 10.1139/L06-095.

Caissie, J., D. Caissie, and N. El-Jabi. 2014. "Hydrologically based environmental flow methods applied to rivers in the Maritime Provinces (Canada)." River Research and Applications 31(6): 651-662. doi: 10.1002/rra.2772.

Daigle, A., A. St-Hilaire, D. Beveridge, D. Caissie, and L. Benyahya. 2011. "Multivariate analysis of the low flow regimes in eastern Canadian rivers." Hydrological Sciences Journal 56(1): 51-67. doi: 10.1080/02626667.2010.535002. 
DEFACC (Department of Environment and Fight Against Climate Change) 2018. Document d'accompagnement de l'Atlas hydroclimatique du Québec méridional. Québec: Ministère de l'Environnement et de la Lutte contre les Changements Climatiques.

DEFACC (Department of Environment and Fight Against Climate Change) 2015. Guide de conception des installations de production d'eau potable, Volume 1. Québec: Ministère de l'Environnement et de la Lutte contre les Changements Climatiques.

DEHAQ (Direction de l'Expertise Hydrique et Atmosphérique du Québec) 2015. « Lignes directrices pour l'estimation des débits d'étiage sur le territoire québécois » Direction d'expertise hydrique du MELCC, February. http://www.cehq.gouv.qc.ca/debitetiage/methode/index.htm

DEHAQ (Direction de l'Expertise Hydrique et Atmosphérique du Québec) 2020. «Rivières (bassins versants): Les régions hydrographiques». Direction d'expertise hydrique $\mathrm{du} \quad$ MELCC. Accessed $23^{\text {rd }}$ January 2020. http://www.environnement.gouv.qc.ca/eau/bassinversant/regionshydro/index.htm\#liste

El-Jabi, N., and D. Caissie. 2018. "Characterization of natural and environmental flows in New Brunswick, Canada." River Research and Applications 35(1): 14-24. doi: 10.1002/rra.3387.

GIEC (Groupe d'experts Intergouvernemental sur l'Évolution du Climat) 2014. Climate Change 2013: The Physical Science Basis. Contribution of Working Group I to the Fifth Assessment Report of the Intergovernmental Panel on Climate Change. Cambridge: Cambridge University Press.

Hersh, R. S., and D. R. Maidment. 2006. "Assessment of hydrologic alteration software". The University of Texas at Austin CRWR Online Report 06-11.

Kite, G. W. 1978. Frequency and Risk Analysis in Hydrology. Water Resources Publications: Fort Collins, Colorado, 224 p.

Linnansaari, T., W. A. Monk, D. J. Baird, and R. A. Curry. 2012. "Review of approaches and methods to assess Environmental Flows across Canada and internationally." Canadian Science Advisory Secretary document 2012-039, vi + 73 pp.

MFFP (Ministère de la Faune, des Forêts et des Parcs) 1999. Politique de débits réservés écologiques pour la protection du poisson et de ses habitats. 4th éd. Québec : Direction de la faune et des habitats, Ministère des Forêts, de la Faune et des Parcs.

Meylan, P., A. C. Favre, and A. Musy. 2008. Hydrologie fréquentielle: Une science prédictive. Lausanne: Presses polytechniques et universitaires romandes.

Olden, J. D., and N. L. Poff. 2003. "Redundancy and the choice of hydrologic indices for characterizing streamflow regimes." River Research.and Applications 19(2): 101-121. doi: 10.1002/rra.700.

Ouellet Dallaire, C., B. Lehner and I. F. Creed. 2019. "Multidisciplinary classification of Canadian river reaches to support the sustainable management of freshwater systems." Canadian. Journal of Fisheries and Aquatic Sciences 77(2): 326-341. 
Pahl-Wostl, C, A. Arthington, J. Bogardi, S. E. Bunn, H. Hoff, L. Lebel et al. 2013. "Environmental flows and water governance: managing sustainable water uses." Current Opinion in Environmental Sustainability 5(3-4): 341-351. doi: 10.1016/j.cosust.2013.06.009.

Poff, N. L. and J. K. H. Zimmerman. 2010. "Ecological responses to altered flow regimes: a literature review to inform environmental flows science and management." Freshwater Biology 55(1): 194-205. doi: 10.1111/j.1365-2427.2009.02272.x.

Poff, N.L, B. D. Richter, A. H. Arthington, S. E. Bunn, R. J. Naiman, E. Kendy, M. Acreman et al. 2010. "The ecological limits of hydrologic alteration (ELOHA): a new framework for developing regional environmental flow standards." Freshwater Biology 55(1): 147-170. doi: 10.1111/j.1365-2427.2009.02204.x.

Poff, N. L., J. D. Allan, M. B. Bain, J. R. Karr, K. L. Prestegaard, B. D. Richter, R. E. Sparks and J. C. Stromberg. 1997. "The natural flow regime: A paradigm for river conservation and restoration." Biosciences 47(11): 769-784.

Poff, N. L. and J. V. Ward. 1989. "Implications of streamflow variability and predictability for lotic community structure: a regional analysis of streamflow patterns." Canadian Journal for Fisheries and Aquatic Sciences 46(10): 1805-1818. doi: 10.1139/f89-228.

Richter, B.D., 2010. "Re-thinking environmental flows: From allocations and reserves to sustainability boundaries." River Research and Applications 26(8): 1052-1063. doi: 10.1002/rra.1320.

Richter, B. D., J. V. Baumgartner, J. Powell, and D. P. Braun. 1996. "A method for assessing hydrologic alteration within ecosystems." Conservation Biology 10(4): 11631174. doi: 10.1046/j.1523-1739.1996.10041163.x.

HCAN (Hydrologie du Canada) 2013. «Hydrologie du Canada » Ressources naturelles Canada, July, 08. https://www.canada.ca/fr/environnement-changementclimatique/services/eau-apercu/volume/surveillance/releves/hydrologie.html

Smakhtin, V.U. 2001. "Low flow hydrology: A review." Journal of Hydrology, 240(3-4): 147-186. doi: 10.1016/S0022-1694(00)00340-1.

Tharme, R. E. 2003. "A global perspective on environmental flow assessment: emerging trends in the development and application of environmental flow methodologies for rivers." River Research and Applications 19(5-6): 397-441. doi: 10.1002/rra.736.

Tennant, D. L. 1976. "Instream flow regimens for fish, wildlife, recreation and related environmental resources." Fisheries 1(4): 6-10. doi: 10.1577/15488446(1976)001<0006:IFRFFW>2.0.CO;2.

USFWS (United States Fish and Wildlife Service) 1981. Interim regional policy for New England streams flow recommendations. Newton Corner (Massachusetts): Memorandum from H.N. Larsen.

WMO (World Meteorological Organization) 2008. Manual on Low flow. Estimation and Prediction. Operational Hydrology Report No.50. Genève: Chairsperson, Publications Board. 